1. Phan Thế Cường, Hoàng Trung Vinh, Nguyễn Anh Trí (2012). Khảo sát tình trạng sắt ở bệnh nhân suy thận mạn giai đoạn cuối trước điêuu trị lọc máu chu kỳ. Tap chí y - dược hoc quân sư, 8, 61-68.

2. Lê Việt Thắng (2011), Nghiên cứu sự thay đổi nồng độ sắt, ferritin huyết thanh bệnh nhân suy thân mạn tính loc máu chu kỳ.Tap chí y học thực hành, 5, 160-162.

3. Nguyến Thi An Thủy, Đỗ Gia Tuyển, Đăng Thi Việt Hà (2018), Đánh giá tình trang dư trữ sắt ơ bệnh nhân suy thận mạn chưa điều trị thay thế qua nồng độ sắt và Ferritin huyết thanh, Tạp chí Nội khoa Việt Nam - số 16.

4. Hoàng Trung Vinh, Phan Thế Cường, Nguyễn Anh Trí (2012). Nghiên cứu biến đổi tình trang sắt ở bệnh nhân suy thân mạn giai đoạn cuối điều tri erythropoietin. Tap chí y hoc thức hành, 9, 24-29.

5. Aleix Casesa, M. Isabel Egocheagab, Salvador Tranchec, et al, (2018) Anemia of chronic kidney disease: 'Protocol of study, management and referral to Nephrology. Nefrología, Vol 38. Issue.1. p1-108

6. KDOQI(2006). Clinicalpractice guidelines and clinical practice recommendations for anemia in chronic kidney disease in adults. Am J Kidney Dis, $47,11-145$.

7. Lucia Del Vecchio, Francesco-Locatelli (2014), Anemia in chronic kidney disease patients: Treatment recommendations and emerging therapies. Expert Review of Hematology 7(4):495-506

8. Manu Venkatesan, Shilpi Saxena, ${ }^{1}$ and Arun Kumar (2019) Evaluation of Iron Status in Patients of Chronic Kidney Disease - A Study to Assess the Best Indicators Including Serum Transferrin Receptor Assay, Indian J Nephrol. 2019 Jul-Aug; 29(4): 248-253.

9. Shaheen F.A., Souqiyyeh M.Z., Al-Attar B.A., et al. (2011). Prevalence of anemia in predialysis chronic kidney disease patients. Saudi J Kidney Dis Transpl, 22(3), 456-463.

\title{
NHẬN XÉT GIÁ TRI MộT SỐ YẾU TỐ TRONG TIÊN LƯỢNG SUY GAN CẤP Ở TRẺ EM
}

\section{TÓM TẮT}

Suy gan cấp (SGC) là môt hội chứng hiếm gặp đặc trưng bởi tổn thương chức năng gan nhanh và trầm trọng ở bênh nhân trước đó không có tổn thương gan. SGC do nhiều căn nguyên gây ra. Trẻ mắc SGC cần được chẩn đoán phát sớm nguyên nhân và tiên lương được tình trang nă̆ng để có hướng xử trí đúng nhằm hạn chế biến chứng, tử vong. Nghiên cứu mô tả tiến hành trên 94 trẻ SGC với đô tuổi trung bình là 10 tháng, trẻ nhỏ tuổi nhất là 2 ngày, trẻ lớn tuổi nhất là 14 tuổi. Nhóm tuổi có tỷ lẹ cao nhất là trẻ nhũ nhi chiếm $44,7 \%(n=43)$, tiếp theo là trẻ nhỏ $43,6 \%$ $(n=42)$. Tré lớn $(\geq 12$ tuối) và trẻ sơ sinh có tỷ lê thấp $7,4 \%(n=7)$ và $4,3 \%(n=4)$. Không có sự khác biệt về giới tính về tỷ lế mắc bênh. Nguyên nhẩn $\mathrm{SGC}$ thường gặp nhất là bệnh chuyển hóa $(23,4 \%)$ với bệnh Wilson, rối loạn chuyển hóa chu trình ure, thiếu hụt citrin là những bệnh chính. Tỷ lệ SGC không rõ nguyên nhân chiếm $47,9 \%$. Các triêu chứng vàng da, bệnh não gan và gan teo nhỏ là các triệu chứng thường găp ở các bệnh nhân có tiên lượng xâu. Xét nghiệm cận lâm sàng có giá trị tiên lượng tử vong là INR cao nhất trên 4,2 với AUC $=0,74$, độ nhay $72,1 \%$, độ đặc hiệu $74,5 \%$, giá trị dự báo dương tính $68,9 \%$, giá trị dự báo âm tính $75,5 \%$ và Bilirubin $\geq 300 \mu \mathrm{mol} / \mathrm{l}$ cho giá trị tiên lượng ở mức độ trung bình với $A U C \geq 0,7$.

*Bệnh viện Nhi Trung ương

Chiu trách nhiệm chính: Nguyễn Pham Anh Hoa

Email: Dranhhoa@nch.org.vn

Ngày nhân bài: 25.01.2021

Ngày phản biên khoa họ: 23.3.2021

Ngày duyệt bài: 29.3.2021
Nguyễn Phạm Anh Hoa*, Mai Thị Giang* lượng

Tư khóa: Suy gan cấp, INR, Bilirubin, yễu tỗ tiên

\section{SUMMARY}

VALUE OF SOME PREDICTIVE FACTORS IN PROGNOSIS PEDIATRIC HEPATIC FAILURE

Acute liver failure (ALF) is a rare syndrome characterized by rapid deterioration of normal liver function following an acute insult in a patient with no previously known underlying chronic liver disease. AHF in children is caused by many causes. Children with SGC need to be diagnosed the cause and prognosis in order to have the manage to minimize complications and death. Descriptive study was conducted on 94 AHF children. The average age of patients is 10 months (2 days- 14 years old). The highest age group was infants, accounting for $44.7 \%$ $(n=43)$, followed by children with $43.6 \%(n=42)$. Older children ( $\geq 12$ years) and infants had a low rate of $7.4 \%(n=7)$ and $4.3 \%(n=4)$. There is no gender difference in incidence. The most common causes of AHF are metabolic diseases (23.4\%). In which, Wilson disease, urea cycle metabolic disorder, and citrin deficiency are the main diseases. The group of unknown etiology AHF is $47.9 \%$. Jaundice, hepatic encephalopathy and hepatic atrophy are common symptoms in patients with a poor prognosis. INR $>4.2$ is the highest predictive test with with AUC $=0.74$, sensitivity $72.1 \%$, specificity $74.5 \%$, positive predictive value $68,9 \%$, a negative predictive value of $75.5 \%$. Bilirubin value $\geq 300 \mu \mathrm{mol} / \mathrm{l}$ is a moderate prognostic value with $A \cup C \geq 0.7$. Keywords: Acute hepatic impairment, INR, Bilirubin, prognostic factors.

I. ĐẶT VẤN ĐỀ 
Suy gan cấp (SGC) là một hội chứng phức tạp, diễn biến nặng do hoại tử tế bào gây suy chức năng gan. SGC do nhiều căn nguyên gây ra. Trẻ mắc SGC cần được chẩn đoán phát sớm nguyên nhân và tiên lượng được tình trạng nặng để có hướng xử trí đúng nhằm hạn chể biến chứng, tử vong. Hiện có một số yếu tố được sử dụng trong tiên lượng SGC nhưng giá trj sử dụng chưa rõ ràng. Chúng tôi tiến hành nghiên cứu đề tài "Giá trị một số yếu tố lâm sàng và cận lâm sàng trong tiên lượng suy gan cấp ở trẻ em" với mục tiêu: "Nhận xét giá trị một số yêu tố lâm sàng và cận lâm sàng trong tiên lượng các bệnh nhân trẻ em có tình trạng suy gan cấp".

\section{II. ĐỐI TƯợNG VÀ PHƯƠNG PHÁP NGHIÊN CỨU}

2.1 Đổi tượng nghiên cứu: Các bênh nhân dưới 18 tuổi được chẩn đoán SGC theo tiêu chuẩn của nhóm nghiên cứu suy gan cấp trẻ em đa trung tâm (PALFSG) năm 2000 bao gồm:

- Không có bằng chứng bênh gan man tính trước đó.

- Có bằng chứng về sinh hóa và/ hoặc lâm sàng của rối loạn chức năng gan

- Rối loạn đông máu không ổn định lại sau dùng vitamin $\mathrm{K}$

+ Phải có bệnh não gan nếu PT bất thường trong khoảng (15,0-19,9s) hoặc INR (1,5-1,9).

+ Có hoặc không có bệnh não gan nếu PT $\geq$ 20s hoặc INR $\geq 2,0$.

2.2. Phương pháp nghiên cứu: Nghiên cứu mô tả hồi cứu và tiến cứu theo ca bệnh được tiến hành tại Bệnh viện Nhi Trung ương từ ngày 01-01-2012 đến hết ngày 30-06-2016.
Chọn cõ̃ mẫu thuân tiện. Các bệnh nhân SGC được phân nhóm hai nhóm tử vong và tiên lượng tốt để so sánh giá trị của các biến số nghiên cứu. Số liêu được thu thâp theo mẫu bệnh án nghiên cứu thổng nhất và xử lý theo chương trình SPSS 20.0 và các thuật toán thống kê y học. Nghiên cứu sử dụng mức ý nghĩa $a=$ 0,05 và khoảng tin cậy $95 \%$.

\section{KẾT QUẢ NGHIÊN CứU}

3.1. Đặc điểm chung của nhóm nghiên cứu: Từ 01/2012 đến 06/2016 có 94 trẻ đủ tiêu chuẩn chẩn đoán suy gan cấp theo tiêu chuẩn PALFSG

Tuổi trung vị của bệnh nhân nghiên cứu là 10 tháng, trẻ nhỏ tuổi nhất là 2 ngày, trẻ lớn tuổi nhất là 14 tuổi. Nhóm tuổi có tỷ lệ cao nhất là trẻ nhũ nhi chiếm $44,7 \%(n=43)$, tiếp theo là trẻ nhỏ 43,6\% $(n=42)$. Trẻ lớn ( $\geq 12$ tuổi) và trẻ sơ sinh có tỷ lệ thấp 7,4\% $(n=7)$ và $4,3 \%(n=4)$.

Bảng 3.1: Đăc điểm về tuổi của đôi tượng nghiên cứu

\begin{tabular}{|c|c|c|}
\hline Nhóm & $\begin{array}{c}\text { Tuối (trung vị) } \\
\text { (khoảng tứ phân vị) }\end{array}$ & $\mathbf{p}$ \\
\hline Tống & $10(3-52)$ & \\
\hline Nhóm 1 (sống) & $8(3-43)$ & 0,7 \\
\hline $\begin{array}{c}\text { Nhóm 2 (tiên } \\
\text { lượng xấu) }\end{array}$ & $12(2-86)$ & 1 \\
\hline
\end{tabular}

Không có sự khác biệt về tuối trung vị giữa hai nhóm bệnh nhân nghiên cứu với kiểm định Mann-Whitney $U, p=0,71>0,05$.

Tỷ lệ nam:nữ= 1,4:1 nhưng không có sự khác biệt về tỷ lệ mắc bệnh giữa trẻ nam và trẻ nữ với $\mathrm{p}=0,12>0,05$.

\subsection{Nguyên nhân gây suy gan cấp}

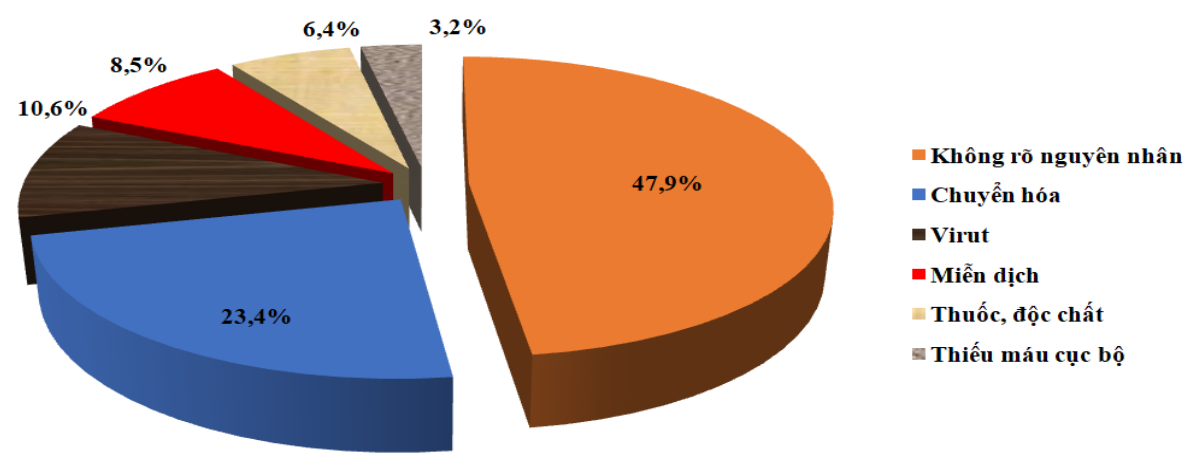

Biểu đồ 1: Các nguyên nhân gây suy gan cấp

3.3. Giá trị tiên lượng của các triệu chứng lâm sàng Bảng 3.2: Đặc điểm lâm sàng và tiền sử

\begin{tabular}{|c|c|c|c|c|c|}
\hline \multirow{2}{*}{ Lâm sàng } & \multirow{2}{*}{$\mathbf{n}$} & \multirow{2}{*}{$\begin{array}{l}\text { Tỷ lệ } \\
\text { (\%) }\end{array}$} & \multicolumn{2}{|c|}{ Kết quả điều trị (\%) } & \multirow[b]{2}{*}{$\mathbf{p}$} \\
\hline & & & Sống & Tiên lượng xấu & \\
\hline Vàng da & 78 & 83,0 & 46,2 & 53,8 & $0,000^{*}$ \\
\hline Bệnh não gan & 44 & 46,8 & 22,7 & 77,3 & $0,000^{*}$ \\
\hline Gan to & 32 & 34,0 & 62,5 & 37,5 & $0,03^{\#}$ \\
\hline
\end{tabular}


TẠP CHÍ Y HỌC VIẸT NAM TẬP 501 - THÁNG 4 - SÓ 1 - 2021

\begin{tabular}{|c|c|c|c|c|c|}
\hline Tiền sử dùng thuốc & 31 & 33,0 & 64,5 & 35,5 & $0,16^{*}$ \\
\hline Sốt & 27 & 28,7 & 44,4 & 55,6 & $0,23^{*}$ \\
\hline Xuất huyết & 21 & 22,3 & 52,4 & 47,6 & $0,85^{*}$ \\
\hline Cố chướng & 19 & 20,2 & 36,8 & 63,2 & $0,09^{*}$ \\
\hline Lách to & 12 & 12,8 & 75,0 & 25,0 & $0,12^{*}$ \\
\hline Tiêu chảy & 8 & 8,5 & 62,5 & 37,5 & $0,72^{\#}$ \\
\hline Nôn & 7 & 7,4 & 57,1 & 42,9 & $1,0^{\#}$ \\
\hline Gan teo nhỏ & 5 & 5,3 & 0 & 100 & $0,03^{\#}$ \\
\hline
\end{tabular}

Chú thích: *: Chi-Square test; \#: Fisher's Exact test

Các triệu chứng vàng da, bệnh não gan và gan teo nhỏ ở nhóm tiên lượng xấu có tỷ lệ cao hơn ở nhóm sống. Sự khác biệt có ý nghĩa thống kê với $p<0,05$.

Bảng 3.3: Đặc điểm cận lâm sàng
\begin{tabular}{|c|c|c|c|}
\hline Cận lâm sàng & Sống (n= 51) & Tiên lượng xấu (n= 43) & p \\
\hline INR nhập viện & $3,2 \pm 1,4$ & $3,9 \pm 2,1$ & $0,89^{*}$ \\
\hline INR chẩn đoán & $2,9 \pm 1,0$ & $4,2 \pm 1,9$ & $0,000^{*}$ \\
\hline INR cao nhất & $4,0 \pm 1,6$ & $5,8 \pm 2,3$ & $0,000^{*}$ \\
\hline Bil nhậ̣p viện & $165,3(39,9-325,8)$ & $245,9(170,1-353,3)$ & $0,02^{\#}$ \\
\hline Bil chẩn đoán & $235,4(42,4-347,6)$ & $299,2(178,6-394,2)$ & $0,01^{\#}$ \\
\hline Bil cao nhất & $278,2(59,8-418,5)$ & $417,6(254,3-509,2)$ & $0,001^{\#}$ \\
\hline Albumin & $33,2 \pm 5,7$ & $29,0 \pm 5,3$ & $0,000^{*}$ \\
\hline GOT & $599,9(136,5-2027)$ & $741,8(213-2423,6)$ & $0,46^{\#}$ \\
\hline GPT & $420,3(111,8-1854)$ & $351(161,4-1341)$ & $0,92^{\#}$ \\
\hline GGT & $72,2(44,6-119,3)$ & $83,9(59,6-120,9)$ & $0,24^{\#}$ \\
\hline ALP & $629,5(385,3-1437)$ & $380,3(249-964)$ & $0,08^{\#}$ \\
\hline NH3 & $135,9(105,4-197)$ & $180,9(144,5-264,4)$ & $0,009^{\#}$ \\
\hline Creatinin & $43,3 \pm 18,9$ & $48,3(40,6-68,7)$ & $0,001^{*}$ \\
\hline Lactat & $4,2(3,0-5,6)$ & $4,9(3,4-7,8)$ & $0,11^{\#}$ \\
\hline LDH & $527,4(397,3-992)$ & $657(414-1332)$ & $0,32^{\#}$ \\
\hline Fibrinogen & $1,8 \pm 0,9$ & $1,4 \pm 0,7$ & $0,01^{*}$ \\
\hline Tiểu cầu & $190(119-260)$ & $100(54-219)$ & $0,004^{\#}$ \\
\hline Hemoglobin & $101,8 \pm 20,4$ & $88,5 \pm 22,9$ & $0,004^{*}$ \\
\hline Bạch cầu & $12,4 \pm 5,8$ & $13,7 \pm 6,8$ & $0,32^{*}$ \\
\hline
\end{tabular}

Chú thích: *: kiếm định T-test; \#: kiểm định Mann-Whitney U

INR nhập viện: INR tại thời điểm nhập viện; INR cao nhất: INR cao nhất ghi nhận được, Bil chẩn đoán: Bilirubin tại thời điểm chẩn đoán; Bil cao nhất: Bilirubin cao nhất ghi nhận được

Các xét nghiệm INR chẩn đoán, INR cao nhất, bilirubin nhập viện, bilirubin chẩn đoán, bilirubin cao nhất, amoniac và creatinin của nhóm tiên lượng xấu có giá trị trung bình hoặc trung vị cao hơn nhóm sống. Ngược lại, các xét nghiệm albumin, fibrinogen, tiểu cầu và hemoglobin của nhóm tiên lượng xấu có giá trị trung bình hoăc trung vị thấp hơn nhóm sống. Sự khác biệt có ý nghĩa thống kê với $p<0,05$.

Bảng 3.4: Giá trị tiên lượng xâu của các biến cận lâm sàng

\begin{tabular}{|c|c|c|c|}
\hline Cận lầm sàng & OR & $\mathbf{9 5 \%} \% \mathbf{C I}$ & $\mathbf{P}$ \\
\hline INR chấn đoán & 1,18 & $0,64-2,16$ & 0,59 \\
\hline INR cao nhất & 1,68 & $1,08-2,61$ & 0,02 \\
\hline Bil nhập viện & 0,99 & $0,98-1,00$ & 0,17 \\
\hline Bil chẩn đoán & 0,99 & $0,98-1,00$ & 0,21 \\
\hline Bil cao nhất & 1,01 & $1,002-1,022$ & 0,01 \\
\hline
\end{tabular}

\begin{tabular}{|c|c|c|c|}
\hline Albumin & 0,88 & $0,76-1,03$ & 0,11 \\
\hline NH3 & 1,00 & $0,99-1,01$ & 0,52 \\
\hline Creatinin & 1,03 & $0,99-1,06$ & 0,78 \\
\hline Fibrinogen & 0,86 & $0,23-3,24$ & 0,82 \\
\hline Tiếu câuu & 1,00 & $0,99-1,01$ & 0,93 \\
\hline Hemoglobin & 0,98 & $0,95-1,02$ & 0,31 \\
\hline
\end{tabular}

Sử dụng phân tích hồi quy đa biến logistic xác định mối liên quan giữa các biến số cận lâm sàng và kết quả điêu trị cho thấy: Giá trị INR và Bilirubin cao nhất là hai biến độc lập liên quan đến tiên lượng xấu với $O R$ lần lượt là 1,68 và $1,01, \mathrm{p}<0,05$.

Bảng 3.5: Đô nhay, độ đăc hiêu, PPV và NPV với điếm cắt INR và Bilïrubin cao nhất

\begin{tabular}{|c|c|c|c|c|c|}
\hline $\begin{array}{c}\text { Xét } \\
\text { nghiệm }\end{array}$ & $\begin{array}{c}\text { Điế̉m } \\
\text { cắt }\end{array}$ & $\begin{array}{c}\text { Độa } \\
\text { nhạy }\end{array}$ & $\begin{array}{c}\text { Độ đặc } \\
\text { hiệu }\end{array}$ & PPV & NPV \\
\hline $\begin{array}{c}\text { INR cao } \\
\text { nhất }\end{array}$ & 4,2 & $72,1 \%$ & $74,5 \%$ & $68,9 \%$ & $75,5 \%$ \\
\hline $\begin{array}{c}\text { Bil cao } \\
\text { nhất }\end{array}$ & 300 & $67,4 \%$ & $52,9 \%$ & $54,7 \%$ & $65,9 \%$ \\
\hline
\end{tabular}


Nhận xét: Với điểm cắt INR cao nhất là 4,2 có độ nhạy $72,1 \%$, độ đặc hiệu $74,5 \%$, giá trị dự báo dương tính $68,9 \%$, giá trị dự báo âm tính $75,5 \%$. Với điểm cắt Bilirubin cao nhất là $300 \mu \mathrm{mol} / \mathrm{l}$ có độ nhạy $67,4 \%$, độ đặc hiệu $52,9 \%$, giá trị dự báo dương tính $54,7 \%$, giá trị dự báo âm tính 65,9\%.

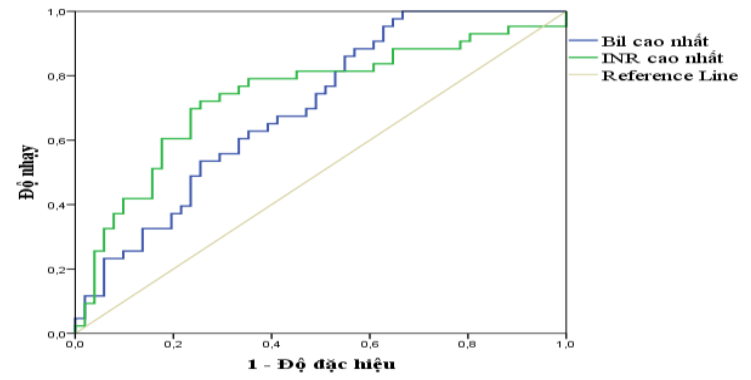

Biểu đồ 3.2: Đường cong ROC và các biến cân lâm sàng trong tiên lượng xâu

Nhận xét: Xét nghiệm INR cao nhất (AUC= 0,74 với $\mathrm{p}=0,000 ; 95 \% \mathrm{CI}=0,64-0,84$ ) có giá trị tiên lượng xấu tốt hơn Bilirubin cao nhất (AUC $=0,7$, với $p=0,001 ; 95 \% C I=0,59-0,8$ ).

\section{BÀN LUÂN}

Bảng 3.2 cho thấy triệu chứng lâm sàng thường gặp nhất là: vàng da, bệnh não gan, gan to, tiền sử dùng thuốc, sốt, xuất huyết và cổ chướng. So sánh sự khác biệt về tỷ lệ các triêu chứng lâm sàng giữa hai nhóm sông và tiển lượng xấu cho thấy tỷ lệ các triệu chứng vàng da, bệnh não gan và gan teo nhỏ ở nhóm tiên lượng xấu cao hơn ở nhóm sống, kết quả này tương tự với tác giả Rajanayagam J.

Kết quả nghiên cứu cho thây các giá trị INR tại thời điểm chẩn đoán, INR cao nhất, bilirubin nhâp viện, bilirubin chẩn đoán, bilirubin cao nhất, amoniac và creatinin của nhóm tiên lượng xấu có giá trị trung bình hoặc trung vị cao hơn nhóm sống. Ngược lại các xét nghiệm albumin, fibrinogen, tiểu cầu và hemoglobin của nhóm tiên lượng xấu có giá trị trung bình hoặc trung vị thấp hơn nhóm sống. Nghiên cứu của Rajanayagam J cũng cho kết quả với INR cao nhất, bilirubin nhập viện, bilirubin cao nhất, lactat ở nhóm tiên lượng xấu cao hơn nhóm sống trong khi AST, ALT, tiểu cầu ở nhóm tiên lượng xấu thấp hơn nhóm sống. Khi phân tích đa biến chúng tôi có kết quả xét nghiệm INR cao nhất và bilirubin cao nhất là các yếu tố có giá trị tiên lượng độc lập cho tiên lượng xấu (Bảng 3.4). Giá trị INR có giá trị cao hơn Bilirubin khi sử dụng cho mục đích tiên lượng xấu. Sử dụng đường cong ROC để đánh giá về giá trị tiên lượng xấu của INR và Bilirubin cao nhất cho thấy INR $\geq 4,2$ và Bilirubin $\geq 300 \mu \mathrm{mol} / \mathrm{l}$ cho giá trị tiên lượng ở mức độ trung bình với $A U C \geq 0,7$, trong đó INR tốt hơn với độ nhạy, độ đặc hiệu, giá trị dự báo dương tính và giá trị dự báo âm tính cao hơn bilirubin. Tác giả Rajanayagam J khi phân tích đa biến và sử dụng đường cong ROC cho kết quả ALT dưới 4660U்/L, Bilirubin cao nhất trên $220 \mu \mathrm{mol} / \mathrm{l}$ và INR cao nhất trên 4,0 có giá trị độc lập trong tiên lượng tử vong, tuy nhiên tác giả này không đưa ra các số liệu về giá trị tiên lượng theo điểm cắt từ đường cong ROC. Các nghiên cứu khác cho một số giá trị dự báo tiên lượng xấu như Lee WS và cộng sự với Bilirubin, ALT, thời gian khởi phát bệnh não gan và thời gian $\mathrm{PT}$; tác giả Kulkarni $\mathrm{S}$ và cộng sự với các biến chứng suy hô hấp cấp, suy thận cấp, bệnh não gan và phù não; tác giả Kathemann và cộng sự với amoniac và albumin . Có sự khác nhau giữa các tác giả có thể do sư khác biệt về số lượng bệnh nhân nghiên cứu và thiết kế nghiên cứu.

\section{KẾT LUÂ̂N}

Suy gan cấp ở trẻ em thường gặp ở trẻ nhỏ. Bệnh thường có diễn biến cấp tính. Nhóm tuổi có tỷ lệ mắc bệnh cao nhất là trẻ nhũ nhi $(44,7 \%)$ và trẻ nhỏ $(43,6 \%)$. Không có sự khác biệt về giới tính về tỳ lệ mắc bệnh. Mồ hình nguyên nhân suy gan cấp đã có sự thay đổi so với các nghiên cứu trước qua đó nguyên nhân thường gặp nhất là bệnh chuyển hóa $(23,4 \%)$ với bệnh Wilson, rối loạn chuyển hóa chu trình ure, thiếu hụt citrin là những bệnh chính. Tỷ lệ không rõ nguyên nhân chẩn đoán là $47,9 \%$. Các triệu chứng vàng da, bệnh não gan và gan teo nhỏ là các triệu chứng thường gặp ở các bệnh nhân có tiên lượng xấu. Xét nghiệm cận lâm sàng có giá trị tiên lượng tử vong là INR cao nhất trên 4,2 với $A U C=0,74$, độ nhạy $72,1 \%$, độ đặc hiệu 74,5\%, giá trị dự báo dương tính $68,9 \%$, giá trị dự báo âm tính $75,5 \%$ và Bilirubin $\geq 300 \mu \mathrm{mol} / \mathrm{l}$ cho giá trị tiên lượng ở mức độ trung bình với $A U C \geq 0,7$.

\section{TÀI LIÊU THAM KHẢO}

1. Squires R.H., Alonso E.M. (2012). Acute liver in children. Liver Disease in Children (4th ed), Cambridge University Press, New York,

2. Squires R.H (2008). Acute Liver Failure in Children. Seminars in Liver Disease, 28 (2), 153-166.

3. Rajanayagam J., Coman D., Cartwright D. et al. (2013). Pediatric acute liver failure: etiology, outcomes, and the role of serial pediatric end- 
stage liver disease scores. Pediatr Transplant, 17 (4), 362-368.

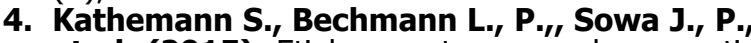
et al. (2015). Etiology, outcome, and prognostic factors of childhood acute liver failure in a German Single Center. Annals of Hepatology, 14 (5), 722-728.

5. Kulkarni S., Perez C., Pichardo C. et al. (2015). Use of Pediatric Health Information System database to study the trends in the incidence, management, etiology, and outcomes due to pediatric acute liver failure in the United States from 2008 to 2013. Pediatr Transplant, 19 (8), 888-895.

6. Lee W. S., McKierna P., Kelly D. A. (2005), Etiology, Outcome and Prognostic Indicators of Childhood Fulminant Hepatic Failure in the United Kingdom. Journal of Pediatric Gastroenterology and Nutrition, 40, 575-581.

\section{HIỆU QUẢ DỰ PHÒNG BÊ̂NH SÂU RĂNG Ở HỌC SINH 12 TUỔI TẠI TỈNH TIỀN GIANG}

\section{TÓM TẮT}

Đặt vấn đê: dự phòng bệnh răng miệng ở trẻ em là vấn đề ưu tiên hàng đầu nhằm giảm gánh nặng do bênh gây ra trong cộng đồng. Mục tiêu: đánh giá hiệu quả dự phòng bệnh sâu răng ở học sinh 12 tuổi tại tỉnh Tiền Giang. Phương pháp: nghiên cứu can thiệp có đối chứng, 1.259 học sinh, không sâu răng được chia thành 3 nhóm, can thiệp giáo dục sức khỏe răng miệng, súc miệng nước Fluor, trám bít hố rãnh trong 18 tháng và đánh giá kết quả sau 30 tháng. Kết quả: sau can thiệp, tỷ lệ học sinh mắc bệnh sâu răng giảm dân ở nhóm chứng, nhóm can thiệp 1 và nhóm can thiệp 2 lần lượt là 48,3\%; 17,2\% và 10,1\%. Hiệu quả can thiệp giữa nhóm can thiệp 1 và 2 so nhóm chứng trên trung bình sâu mất trám răng (SMTR) và sâu mất trám mặ̆t răng (SMTMR) tăng lần lượt là $1225 \%-1300 \%$ và $850,6 \%-856,3 \%$. Hiêu quả dư phòng bệnh sâu răng ở nhóm can thiệp 2 cao hơn nhóm can thiêp 1. Sau trám bít hố rãnh bằng Fuji VII: tỷ lệ học sinh mắc bệnh sâu răng ở nhóm can thiệp $(1,8 \%)$ thấp hơn nhóm chứng $(9,3 \%)$; hiệu quả can thiệp giữa nhóm can thiệp so nhóm chứng trên trung bình SMTR và SMTMR tăng lần lượt là $583,3 \%$ và 300\%. Kết luận: hiệu quả dự phòng bệnh sâu răng tăng cao khi phối hợp các biện pháp can thiệp. Các biện pháp dự phòng bệnh ở học sinh 12 tuổi tại tỉnh Tiền Giang đã mang lại hiệu quả cao.

Từ khóa: sâu răng, SMTR, SMTMR, Tiền Giang.

\section{SUMMARY}

\section{EFFICIENCY OF DECAY TOOTH}

\section{PREVENTION IN 12-YEAR-OLD CHILDREN} IN TIEN GIANG PROVINCE

Background: prevention of oral diseases in children is the priority issue to reduce the burden

\footnotetext{
*Bệnh viện Đa khoa Trung tâm Tiền Giang

**Trướng Đai hoc Y Dước Cần Tho

Chịu trách nhiệm chính: Lê Hoàng Hạnh

Email: lehoanghanh2707@gmail.com

Ngày nhận bài: 19.01.2021

Ngày phản biên khoa hoc: 18.3.2021

Ngày duyệt bài: 26.3.2021
}

\section{Lê Hoàng Hạnh*, Tạ Văn Trầm*, Lê Thành Tài**, Trần Thị Phương Đan**}

caused by oral disease in the community. Objective: in order to evaluate tooth decay prevention's effectiveness among 12-year-old students in Tien Giang province. Methods: using controlled intervention study, 1259 students who have no tooth decay divided into 3 groups, oral health education intervention, fluoride mouthwash, dental fissure filling for 18 months, and evaluation of outcomes results after 30 months. Results: after the intervention, the percentage of students with tooth decay gradually decreased in the control group, intervention group 1, and intervention group 2 , respectively $48.3 \%, 17.2 \%$ and $10.1 \%$. The intervention efficiency between intervention group 1 and 2 compared with the control group was on average Decayed Missing Filled Teeth (DMFT) and Decayed Missing Filled Surfaces (DMFS) increased $1225 \%-1300 \%$ and $850.6 \%-856.3 \%$. The preventive effect of tooth decay in the intervention group 2 was higher than the intervention group 1. After filling the pit tooth groove with Fuji VII: the percentage of students with tooth decay in the intervention group (1.8\%) was lower than the control group (9.3\%); the intervention efficiency between the intervention group compared to the control group on the mean DMFT and DMFS increased by $583.3 \%$ and $300 \%$ respectively. Conclusion: the effectiveness of tooth decay prevention increased when combining interventions. Preventive measures for 12-year-old students in Tien Giang province have been highly effective.

Keywords: tooth decay, DMFT, DMFS, Tien Giang.

\section{I. ĐĂT VẤN ĐỀ}

Tai Việt Nam, nhiều năm qua, dù ngành y tế đã nỗ lực triển khai nhiều biện pháp mạnh mẽ kết hợp các chương trình dự phòng, can thiệp cộng đồng nhưng tỷ lệ bệnh sâu răng ở Việt Nam còn rất cao, đặc biệt là ở trẻ em và người cao tuổi. Thực trạng đáng báo động hiện nay là khoảng $90 \%$ người dân có vấn đề về răng miệng, chủ yếu là mắc bệnh sâu răng; tỷ lệ trung bình răng sâu mất trám ở trẻ 5-6 tuổi khoảng 50-60\%, đặc biệt ở lứa 12 tuổi đến 80$85 \%$; tỷ lệ sâu răng sửa ở trẻ là $85-90 \%$, gây 